\title{
La representación axiológica del género y la orientación sexual en libros de texto de inglés para Secundaria
}

\author{
JuAN RAMÓn GuiJarRo OJEDA \\ Facultad de Educación y Humanidades de Melilla \\ Universidad de Granada
}

Recibido: 22 febrero 2005 / Versión aceptada: 15 abril 2005

ISSN: $1697-7467$

\begin{abstract}
RESUMEN: En este artículo estudiamos los valores que transmite una selección de libros de texto de inglés para secundaria en relación al género y a la orientación sexual. El objetivo principal que perseguimos con este trabajo es llamar la atención sobre el rol central que juegan los libros de texto en la transmisión y perpetuación de los estereotipos sociales relacionados con los parámetros señalados anteriormente. Para llevar a cabo nuestro estudio hemos seleccionado cinco libros de texto de Educación Secundaria que se utilizan actualmente para la enseñanza del inglés como lengua extranjera. Los manuales corresponden a cinco editoriales diferentes, para ofrecer una amplia perspectiva sobre los valores transmitidos en relación con estas variables. De la descripción y análisis del corpus seleccionado obtendremos una serie de conclusiones acerca del tratamiento dado a la transversalidad, a la diversidad y a las diferencias intrísecas a la otredad ${ }^{1}$. Podremos constatar así, si se transmiten valores sexistas, heterosexistas u homófobos, bien sea de forma manifiesta o latente.
\end{abstract}

Palabras clave: Lengua extranjera, libros de texto, transversalidad, otredad, cultura, género, orientación sexual.

\begin{abstract}
In this paper we analyse a series of EFL textbooks for Secondary School according to gender and sexual orientation axiological parameters. With this article we aim at focusing on the central role textbooks play in the transmission and perpetuation of social stereotypes related to identities. To carry out this research we have selected five textbooks which are currently being used in Spain in Secondary Education. These coursebooks have been edited by five different publishing houses to offer a wide perspective on otherness-related values. After describing and analyzing the corpus, we will discuss the way cross-curricular education and otherness-related differences are treated. We will be able to prove whether the textbooks selected transmit sexist, heterosexist, or homophobic values in an explicit or implict way.
\end{abstract}

Key words: Foreign Language, textbooks, cross-curricular education, otherness, culture, gender, sexual orientation.

${ }^{1}$ Cuando Rodríguez López-Vázquez (2001) o Heredia Maya (2000, 2001) utilizan el término Otro, y de ahí Otredad, piensan en las formas sociales o psicológicas mediante las cuales un grupo excluye o margina a otro. Al declarar a alguien como Otro, las personas tienden a centrarse en lo que le hace diferente o contrario, desembocando en imágenes estereotípicas. Esta situación también se hace extensible a las decisiones y relaciones políticas y a las prácticas culturales. 


\section{INTRODUCCIÓN}

La importancia del análisis de libros de texto para nuestro estudio es su demostrada unicidad como fuente de información que existe en opinión del profesorado de Lengua Extranjera (Jiménez Catalán, 1997; Burke, 2000). Son muchas las razones que, desde los estudios de didáctica de la lengua y la literatura, se ofrecen para enriquecer los manuales que vienen dados por las editoriales, pero la realidad de las aulas, la falta de tiempo, la escasez de incentivos profesionales y de reconocimiento personal y profesional [comunicaciones personales] abocan al profesorado al seguimiento lineal de los parámetros instructivos y educativos que proponen los grupos editoriales. En palabras de Selander (1995: 132), "el libro de texto es el material más importante para el profesor y para el alumno. No es más ni menos que la casi totalidad del currículum".

Debido a esta relevancia de los manuales dentro del proceso de enseñanza y aprendizaje de la lengua extranjera se hace imperante la posición de Selander (1995: 130) al afirmar que:

Los libros de texto y todos los materiales escolares pueden ser perfectamente estudiados y considerados como una representación de los intereses de una sociedad e igualmente como modelos subliminales y paradigmáticos de una forma de pensar, de una mentalidad.

Teniendo en cuenta la posición anterior, podemos afirmar que los libros encierran un currículum oculto, paralelo al manifiestamente explícito:

[...] the 'hidden curriculum': the image of life presented by coursebooks, the attitudes they convey, consciously or unconsciously, and the social and cultural values that they communicate (Cunningsworth, 1995: 86).

En este sentido, no sólo hay que valorar positiva o negativamente lo que aparece en un manual; sino que es mucho más importante lo que no aparece ya que, a menudo, las situaciones más graves de discriminación no vienen dadas por el tratamiento erróneo de un tópico determinado, sino por la omisión del mismo desterrándolo del canon preestablecido y legitimado social y culturalmente.

\section{2. ОвJetivos}

Siguiendo el eje central que guía este trabajo, los objetivos principales de esta investigación son:

- Recoger de forma detallada los elementos de otredad en relación al género y la orientación sexual que aparecen en el corpus seleccionado;

- Analizar cualitativamente los diferentes ítems encontrados atendiendo al tipo de texto escrito o visual, a los conceptos, procedimientos y actitudes, al tratamiento que se da a su inclusión, así como a otros aspectos que puntualmente puedan ser considerados de interés para nuestro estudio; 
JuAN RAMÓn GuiJarRo OJEDA La representación axiológica del género y la orientación sexual ...

- Crear conciencia entre el profesorado de Lengua Extranjera sobre la presencia de un potente currículum oculto en los libros de texto;

- Descubrir si en el corpus seleccionado de libros de texto y editoriales existen valores sexistas u homófobos, tomando como referentes los estereotipos y clichés en torno a estas variables.

\section{REVISIÓN DE LITERATURA SOBRE ANÁLISIS DE LIBROS DE TEXTO}

Si revisamos la literatura que compete al campo de estudio de análisis de libros de texto, enseguida nos damos cuenta de que no existe una base lo extensamente consolidada como pudiera parecer a primera vista.

Por un lado, tenemos los estudios que hablan sobre diseño curricular que, aunque no hacen referencia explícita al ámbito de lenguas extranjeras, nos pueden dar una idea general de los parámetros que hay que tener en cuenta a la hora de diseñar materiales específicos para un determinado curso (ver Dubin y Olshtain, 1986; Munby, 1978; Johnson, 1982).

Un segundo bloque temático dentro de los estudios de manuales, sería el que comprende los trabajos de análisis de libros de texto propiamente dichos (ver Cunningsworth 1984; McDonough y Shaw 1993; Sheldon 1988). En estos estudios encontraremos directrices útiles para seleccionar libros de texto atendiendo a las características específicas o necesidades del grupo-clase objeto de enseñanza.

Finalmente, y en el contexto de investigación español, hallamos los trabajos de Miranda (1990), Rueda (1994), Molina (1994) o Jiménez Catalán (1997). Estas investigaciones tienen como objeto de estudio el análisis práctico de materiales para la enseñanza y aprendizaje de lenguas extranjeras. Se analizan aspectos varios como el vocabulario o las discriminaciones por razón de sexo en imágenes y textos.

\section{Metodología}

En la literatura actual sobre el análisis de manuales no existe un consenso unánime en relación a los criterios que pueden utilizarse para evaluar un libro de texto; será cada profesor/ a o investigador/a quien tendrá que formular sus propias preguntas dependiendo de cuáles sean los objetivos que pretende alcanzar con su curso o su investigación.

Nosotros analizaremos los contenidos axiológicos del corpus seleccionado atendiendo a las siguientes variables:

1) Variable de género

2) Variable de orientación sexual

Los ítems analizados harán referencia tanto a los elementos manifiestos como latentes bien sea en forma de textos escritos, gráficos o actividades de explotación didáctica de los mismos. De igual forma, consideraremos especialmente la omisión de las variables de las diferencias que estamos estudiando.

Con tal fin, seguimos algunas de las directrices dadas por Cunningsworth (1995) que ofrece una batería de preguntas para evaluar los libros de texto de lenguas extranjeras. Las 
clasifica en varios epígrafes que nos pueden dar una idea sobre los aspectos básicos en los que debemos reparar a la hora de sacar la máxima información posible sobre los manuales utilizados en el aula. Para nuestro estudio resulta especialmente relevante la batería que hace relación a los contenidos:

Checklist for topic and subject content:

- Are real topics included in the coursebook? If so, how varied are they?

- Will the coursebook contribute to expanding learners' awareness and enriching their experience?

- Does it relate to and engage the learners' knowledge system, i.e., the knowledge of the world that they bring with them?

- Are the topics sophisticated enough in context for the learners, but at the right level linguistically?

- Do they actually do what they set out to do? If informative, do they inform, if humorous, do they amuse, if controversial, do they challenge, etc.?

- Are they suitable for the age group?

- At school level, do they link in with other subjects (e.g. history, geography, science)? (Cunningsworth, 1995: 90).

Estas preguntas nos ayudarán a dilucidar una serie de valores socialmente establecidos que pertenecen al orden hegemónico. Es evidente que un libro de texto, como parte integrante del currículo en general, no puede ser neutral ideológicamente hablando. En palabras de numerosos pedagogos, "this hidden curriculum is more effective than the stated official curriculum because it pervade most aspects of education" (Cunningsworth, 1995: 90).

Además del contenido que aparece en los libros de texto, es especialmente relevante el papel que juegan los personajes que en él aparecen. Los personajes, en contraposición al contenido, transmiten un componente afectivo que está cargado de sentimientos, subjetividad y valores (Ibíd., 91). En la era de la comunicación, a ningún adolescente le es indiferente una estrella de pop o un afamado deportista o actor/actriz. Una estrella determinada puede trasmitir unas motivaciones, miedos, esperanzas, odios o admiraciones que van a influir definitivamente en el alumnado y van a ir forjando su carácter y, consecuentemente, su modo de ver la vida y actuar en ella.

Un tercer aspecto que se refleja en los libros de texto es el de la sociedad y el de las estructuras sociales, íntimamente relacionado con los valores:

In some coursebooks the characters exist in some kind of social network, whether the focus is on the family, the peer group or the workplace, and interact with one another. But in others, characters pop up from nowhere, sometimes just as embodied just as disembodied voices in a dialogue, and disappear just as quickly. This fragmented portrayal of social relationships (or lack of them) does little to give credibility to the characters, does not help learners to relate to them and provides little context for meaningful language learning (Cunningsworth, 1995: 91).

En relación con este tercer bloque para ser examinado en los libros de texto (valores sociales y culturales), seguimos la propuesta de Cunningsworth (1995) que ha de guiarnos a la hora de valorar el potencial axiológico de un manual: 
JuAn RAMÓn GuiJarRo OJEDA La representación axiológica del género y la orientación sexual ...

- Are the social and cultural contexts in the coursebook comprehensible to the learners?

- Can learners interpret the relationships, behaviour, intentions, etc. of the characters portrayed in the book?

- Are women given equal prominence to men in all aspects of the coursebook?

- What physical and character attributes are women given?

- What professional and social positions are women shown as occupying?

- What do we learn about the inner lives of the characters?

- To what extent is the language of feeling depicted?

- Do the coursebook characters exist in some kind of social setting, within a social network?

- Are social relationships portrayed realistically? (Cunningsworth, 1995: 92).

\section{Corpus de estudio}

Para llevar a cabo nuestro estudio hemos seleccionado cinco libros de texto que se utilizan actualmente en Secundaria para la enseñanza del inglés como lengua extranjera. Corresponden a cinco editoriales diferentes con objeto de ofrecer una amplia perspectiva sobre los temas transversales y los valores relacionados con la otredad.

Hemos seleccionado este corpus de estudio por tres razones fundamentales: 1) los libros de texto han sido creados por editoriales utilizadas en Educación Secundaria en lengua extranjera para el mercado español; 2) todos estos libros de texto cuentan con el visto bueno de las autoridades competentes en materia educativa en el contexto español; y 3) todos afirman seguir las directrices marcadas por la LOGSE en relación a la enseñanza de la lengua extranjera en las etapas obligatorias de la educación: a) se adecuan a la etapa que atraviesa el alumnado; b) siguen el enfoque comunicativo de enseñanza para las lenguas; c) la conciencia linguiística y personal está muy presente; d) la interdisciplinaridad como eje vertebrador; e) todas las tareas propuestas deben fomentar la autonomía del aprendizaje por parte del alumnado; f) atención a la diversidad; g) los contenidos se organizan siguiendo las directrices del enfoque por tareas y proyectos; y h) se contemplan los temas transversales (Jiménez Catalán, 1997).

A continuación detallamos el corpus de estudio correspondiente a libros de texto de Inglés para la Educación Secundaria Obligatoria:

Editorial Oxford University Press:

WILDMAN, J., N. WHITNEY, \& T. FALLA (1999):'Thumbs up! 2. Oxford:

OUP. (Guía didáctica para el profesor 2; Student's Book 2; Workbook 2).

Editorial Longman:

MOHAMED, S. \& R. ACKLAN (1993): The Pre-Intermediate Choice. The

Beginners' Choice. Longman. Great Britain. (Student's Book; Workbook).

Editorial Cambridge University Press:

PUCHTA, H. y J. STRANKS (2004): English in Mind. Cambridge: Cambridge University Press. (Student's Book; Workbook).

Editorial Express Publishing:

DOOLEY, J. \& V. EVANS (2004): Blockbuster 1. Newbury: Express Publishing. (Student's Book; Workbook \& Grammar Book). 


\section{Editorial Burlington Books:}

FIELD, P. et al. (1998): Top Class 3. Limassol, Cyprus: Burlington Books.

(Teacher's Manual; Teacher's Edition; Student's Book).

De la descripción y análisis de los manuales anteriores se obtendrán importantes conclusiones acerca acerca de la representación axiológica del género y de la orientación sexual en los mismos. Evidentemente, las casas editoras juegan roles sociales, culturales y axiológicos que hacen que unos valores determinados sigan perpetuándose o no en la sociedad a través de su inculcación en las generaciones jóvenes. Estos valores no sólo se perpetúan por su plasmación explícita en el manual, sino que aquellos elementos que se omiten son aún más significativos desde el punto de vista axiológico. En este sentido, podríamos decir que aquello que no se nombra no existe.

\section{AnÁlisis y discusión de los Resultados}

\subsection{Editorial Burlington Books}

\section{Variable de género}

Burlington Books ha optado por incluir la igualdad de género en una serie de parcelas de la vida social, cultural y deportiva en el que no lo pareciera a primera vista. Esta inclusión de la mujer en plenitud de igualdad con el hombre en actividades que han pertenecido tradicionalmente al género masculino resulta altamente productiva desde el punto de vista de la educación axiológica.

El transversal de Educación para la igualdad de sexos no se presenta de forma explícita en una unidad concreta que gira en torno a conceptos, procedimientos y actitudes. No obstante, es de primordial importancia que se incluyan imágenes y textos que normalicen el papel de la mujer en parcelas que no ha ocupado tradicionalmente.

A continuación presentamos algunos de los tópicos más relevantes que ejemplifican las ideas comentadas anteriormente.

Ítem 1. Se presenta el tema "Extreme Sports". Para ilustrar el texto se presenta tanto a un hombre como a una mujer. Esta inclusión de la mujer dentro de los deportes de riesgo, indica a los estudiantes que hay una igualdad bastante generalizada en un terreno que hace algún tiempo era dominio exclusivo del género masculino (páginas 22-23).

Ítem 2. Una mujer es presentada haciendo 'puenting', uno de los deportes de riesgo por excelencia. Nuevamente, resulta muy positivo el tratamiento que esta editorial da al tópico del género en relación a los deportes, borrando las imágenes sexistas y haciendo ver al estudiante la existente igualdad social de los géneros (página 25).

Ítem 3. Se presenta a la campeona del mundo de vela Theresa Zabell. En la actividad propuesta, los estudiantes tienen que contestar ocho preguntas de elección múltiple sobre su tiempo libre, cuándo empezó a navegar, si practica otros deportes o qué premios ha ganado. Es muy positivo el hecho de que se introduzca una mujer para ilustrar a una deportista y campeona de élite (página 27). 
JuAn RAmón GuiJarRo Ojeda La representación axiológica del género y la orientación sexual ...

Ítem 4. La sección de audición titulada "A lecture" es una actividad sobre la evolución del vestido de las mujeres. Esta actividad puede ser muy beneficiosa para trabajar cuestiones relacionadas con el género, sobre todo, porque la evolución de la moda en la mujer nos puede dar una idea clara de su lucha contra la sociedad del patriarcado.

La actividad consiste en decir si son verdaderas o falsas las siguientes cuestiones:

- We can learn a lot about culture by looking at the clothes people wear.

- During World War II, many women wore trousers because they had to work at men's jobs.

- After World War II, women wore very feminine clothes.

- In the 60 s, women of all ages wore mini-skirts. (etc.)

A partir de este texto, aunque los alumnos/as no tengan un dominio muy avanzado de la lengua, el profesor/a puede diseñar multitud de actividades para conseguir objetivos relacionados con la otredad como transversalidad en lengua extranjera (página 35).

Ítem 5. La Unidad 13 se titula "Women in Space". Afortunadamente, está dedicada a la importancia que han tenido las mujeres también en la carrera por la conquista del espacio. En las páginas 106 y 107 se presenta a las astronautas Sally Ride (1951- ...) y Christa McAuliffe (1948-1986).

Se trata de una extraordinaria labor de magnificar la labor de la mujer en un terreno de hombres y de máxima élite. La actividad propuesta para trabajar con estos textos consiste en hacer preguntas de comprensión textual. Se trata de preguntas poco significativas para la importancia desde el punto de vista de la otredad de género que tienen estos textos:

- What three things did the astronauts do during their mission in 1984 ?

- What is Dr Ride doing professionally at the moment?

- Did Christa McAuliffe teach at high school while she was training for the flight?

- How long after the launch did Challenger explode?

- How old was Christa McAuliffe when she was killed? (pp. 106-107).

A partir de estas actividades, el profesorado puede generar otras preguntas que tengan relación directa con la reflexión y el debate en torno a cuestiones de igualdad de sexos. Al no tratarse de un transversal propiamente diseñado dentro del libro de texto, el potencial axiológico de esta actividad recae en el grado de conciencia del propio docente.

\section{Variable de orientación sexual}

El tema de la diversidad en relación a la orientación sexual no es tratado ni explícita ni implícitamente por esta editorial en los libros de texto. Sin embargo, sí existen una serie de situaciones y de imágenes que aparecen en el manual que podrían presentarla y, sin embargo, se opta por una tendencia heterosexual. Nos referimos a la presentación de los diferentes modelos de pareja o de familia, que son parte de la identidad de las personas. Las imágenes sobre parejas y familias son muy recurrentes a lo largo de todo el manual y, sin embargo, siempre corresponden a parámetros heterosexuales. 


\subsection{Editorial Express Publishing}

\section{Variable de género}

Express Publishing, teniendo en cuenta los datos recogidos, se presenta bastante controvertida en relación a los temas de igualdad de género. Este tópico no se constituye en unidades transversales explícitas, pero aparecen en todo el manual numerosas imágenes, textos y actividades que pueden resultar sexistas.

A continuación presentamos algunos de los ejemplos más sobresalientes al respecto:

Ítem 1. Aparece la imagen de una familia en un puerto deportivo. La familia está formada por un padre, una madre, una hija y un hijo.

En una de las actividades propuestas denominada "Listen, read and talk about..." aparece un epígrafe donde hay que hablar sobre los "family members". La actividad propuesta sobre esta fotografía no da mucho pie a la activación de un debate en torno a las consideraciones más postmodernas de la pluralidad que puede conllevar una familia. Si ya de entrada se presenta al alumnado un prototipo de familia, muy difícilmente va a poder deconstruir los esquemas patriarcales recibidos en torno a la identidad, el género, la familia o los roles sociales atribuidos a cada sexo, género o personas de diferente orientación sexual. En este caso, todo quedará en manos de la conciencia y del buen hacer del profesor/a respecto a temas de otredad y cómo podrían explotarse metodológicamente en el área de Lengua extranjera (página 4).

Ítem 2. La unidad 6 gira en torno a las diferentes profesiones características de las sociedades avanzadas. A continuación presentamos las personas, sus nombres y sus profesiones:

$\begin{array}{ll}\text { Rosa, maestra } & \text { Marco, peluquero } \\ \text { Hanna, estudiante } & \text { Glenda, enfermera } \\ \text { Barry, cartero } & \text { John, piloto } \\ \text { Anita, recepcionista } & \text { Bob, médico }\end{array}$

En este caso se reproducen algunos tópicos: en el campo de la salud, mientras que el hombre es el médico, la mujer es la enfermera. En educación, la maestra es una mujer, Rosa de Brasil. Se trata de una profesión tradicionalmente cubierta por mujeres como se puede comprobar en cualquier manual de sociología de la educación (páginas 22-23).

Ítem 3. La unidad 16 se titula "Working with animals". Todas las imágenes que aparecen son de hombres: un jinete de carreras, un cuidador de zoo, un encantador de serpientes, dos policías a caballo y un granjero. Todas las actividades relacionadas con el trato y cuidado de animales están desarrolladas por hombres. Evidentemente, como se hacía en las páginas 2223 al presentar a María como veterinaria, hay multitud de imágenes, textos y actividades que se podrían haber empleado para ofrecer una imagen no sexista del mundo de "Working with animals" (páginas 54-55).

Ítem 4. Nuevamente, en relación a las cuestiones de otredad en relación al género, encontramos la unidad 18 titulada "Actions". La actividad trabaja el presente simple en todas 
JuAn RAMÓn GuiJarRo OJEDA La representación axiológica del género y la orientación sexual ...

sus formas: afirmativa, negativa, interrogativa y de 'short answers'. Axiológicamente hablando, se trata de un ejercicio muy significativo porque se explotan los roles de género perpetuando geométricamente los valores del patriarcado. A continuación detallamos las tareas asignadas a mujeres y a hombres:

La mujer cocina, canta, pinta y escribe.

El hombre baila, cuenta, escribe, lee y conduce.

Claramente, una editorial no puede afirmar que su libro de texto está diseñado siguiendo los dictados del Marco europeo de referencia para la enseñanza de lenguas y luego presentar estos clichés de género tan acusados, sobretodo, cuando este documento vela especialmente para que los estudiantes sean expuestos a las diferentes situaciones de otredad para construir ciudadanos axiológicamente valiosos que saben reconocer las diferencias y actuar constructivamente ante las situaciones discriminatorias que éstas pudieran reproducir:

[...] the difficulty of a task which introduces new sociocultural knowledge and experiences will be affected by, for example: the learner's interest in and openness to otherness; willingness to relativise his or her own cultural viewpoint and value system; willingness to assume the role of 'cultural intermediary' between his or her own and the foreign culture and to resolve intercultural misunderstanding and conflict (Consejo de Europa, 2001: 161).

De poco nos sirve, en este sentido, que las mujeres continúen dedicándose a cocinar y a cantar en coros, y los hombres a realizar actividades que requieren preparación y educación formal como pueden ser leer, escribir o conducir un coche. Pero, claramente, estas actividades asignadas a los chicos son las que en un futuro permiten controlar los hilos del mundo económico, cultural, etc. y continuar perpetuando el machismo y las convenciones sexistas que dejan a la mujer viviendo el devenir social como mera espectadora (página 58).

Ítem 5. La unidad 41 se titula "Fame and Pride". Se dan una serie de imágenes de personajes famosos de la historia. En total son 12 imágenes de las que tan sólo dos corresponden a mujeres: Agatha Christie y Marie Curie. Los hombres son: Neil Armstrong, Yuri Gagarin, Elvis Presley, Frank Sinatra, John F. Kennedy, Albert Einstein, Tchaikovsky, Leonardo da Vinci, Chistopher Columbus y Wilbur y Orville Wright.

El primer asunto que nos llama la atención es el desproporcionado número ofrecido entre hombres y mujeres famosos cuyas actuaciones han sido significativas para el devenir de la historia.

El segundo aspecto que viene a reflejar esta oferta de personajes es la presentación de personalidades que solamente pertenecen a la cultura occidental y dominante. Sin embargo, hay muchos más personajes como Gandhi, por ejemplo, que es más importante que muchos de los presentados y no tienen un hueco en el libro de texto. Quizá se deba esta omisión a que es una forma de discriminación, a que Gandhi no pertenece a la cultura dominante occidental, además de representar un peligro inminente para la perpetuación de la misma (páginas 134-135).

Ítem 6. Encontramos el ejercicio 9 "Look at the pictures and make sentences". Es una actividad que perpetúa la discriminación de género porque las tres mujeres que aparecen en 
las fotos se dedican a elegir flores, a comprar ropa y a cocinar. Sin embargo, Bob, el único chico que aparece, se dedica a entrenar duramente en bicicleta de montaña porque quiere participar en las Olimpiadas del próximo año (página 122).

\section{Variable de orientación sexual}

En relación a la orientación sexual, no hay referencias explícitas ni implícitas que recojan las diferencias en torno a este tipo que otredad que, además, genera mucha discriminación en la sociedad. Simplemente podemos afirmar que se omite en todos los sentidos tanto en temas de pareja como en temas de familia.

Siempre que se presentan parejas están formadas por hombre-mujer o siempre que aparecen familias están formadas por hombre-mujer; no dándose cuenta de la gran diversidad que existe actualmente en relación a las cuestiones de identidad sexual.

\subsection{Editorial Longman}

\section{Variable de género}

Ítem 1. Se nos presenta la actividad titulada "Football fanatism". Extraído del semanario 'Living', este texto intenta acercarnos a la realidad del fútbol que se vive en Inglaterra. Aquí entran en juego muchos factores. Por ejemplo, el texto utiliza a una mujer como fanática del equipo 'Swansea'. Este hecho está bien porque no solamente es el fútbol un deporte "de hombres" y además se integra a la mujer en todos los aspectos de la vida social, incluso en el fútbol que ha sido tradicionalmente "cosa de hombres" (p. 37).

Ítem 2. "Love and Marriage in Britain". El texto es realmente motivador para los adolescentes porque trata sobre amor y matrimonio que tanto les fascina. Sobre todo aporta datos acerca de una situación que está cambiando y no es que sea peor; sino simplemente diferente. Ahora uno de cada cuatro hijos/as nace fuera del matrimonio, el $30 \%$ de las relaciones acaban en divorcio y son las mujeres las que antes lo piden. Finalmente, se comenta que el número de matrimonios aumenta cada día por el miedo al SIDA y porque investigaciones revelan que los casados viven más.

Como es normal, los matrimonios que se presentan son hombre-mujer y socialmente, los matrimonios de homosexuales aún no pueden adoptar hijos (p.120).

\section{Variable de orientación sexual}

No existen datos positivos ni negativos al tratamiento de la orientación sexual en este manual. La tónica imperante es la omisión de dichos elementos.

\subsection{Editorial Oxford University Press}

\section{Variable de género}

En relación a las cuestiones de diferencia de género, los ejemplos que presenta esta editorial suponen la perpetuación de varios estereotipos que se asignan al rol de ser mujer o de ser hombre. Como viene siendo tradicional, estos temas de Educación para la igualdad de sexos no se organizan en lecciones independientes que tratan axiológicamente estos tópicos; 
JuAN RAMÓn GuiJarRo OJEDA La representación axiológica del género y la orientación sexual ...

sino que, de forma aislada y puntual aparecen imágenes o textos insertados en las diferentes unidades que presenta el libro de texto.

A continuación vemos algunos ejemplos que ilustran la situación explicada anteriormente:

Ítem 1. Aparece un chico vestido de futbolista para señalar las partes del cuerpo. Evidentemente esto hace honor a la realidad porque el mundo del fútbol está dominado por los chicos. Pero no olvidemos que hay multitud de chicas que juegan al fútbol. El problema reside en que sus voces están siendo silenciadas por los medios de comunicación.

Aún en nuestros días, el fútbol sigue siendo "cosa de hombres" y lo que es peor, nadie se inmuta por cambiar la realidad que se está transmitiendo a las nuevas generaciones. Todos sabemos que son muchas las mujeres que juegan en la actualidad al fútbol pero a nadie interesa exponer esa realidad a los adolescentes.

Las razones más profundas de esta situación deberíamos encontrarlas en la construcción de los géneros desde que somos pequeños. Por ejemplo, la razón por la cual los chicos no quieren que las chicas jueguen al fútbol reside en la creencia, por parte de los primeros, de que si las mujeres participan en algo que tradicionalmente pertenece a los hombres, entonces éstos corren el riesgo de ser tachados de 'gays' por el resto de la sociedad. Y posiblemente, éste sea el mayor de los estigmas posibles con los que pueda crecer un adolescente masculino. Ante esta situación, la solución es clara: excluir a las mujeres del grupo dominante que ostenta el poder cultural en los adolescentes (p. 5).

Ítem 2. Aquí se habla sobre las profesiones y se ofrecen imágenes de personas para cada una de ellas:

Chef: mujer

Farmer: hombre

Hairdresser: mujer

Journalist: mujer

Mechanic: hombre
Nurse: mujer

Bus driver: mujer

Shop assistant: hombre

Computer programmer: hombre

Tour guide: mujer

La actividad presenta el tema del mundo profesional en relación a los géneros. Hay algunos ejemplos claros de la sociedad patriarcal como puede ser que la enfermera sea una mujer, el mecánico un hombre y el programador de ordenadores también un hombre. Sin embargo, nos parece muy positivo que se presente a una mujer como conductora de autobuses urbanos, así como también en el rol de chef, o al hombre como cajero de un supermercado.

Con imágenes de este tipo, bien podrían empezarse a romper los estereotipos que tradicionalmente van asociados a las cuestiones profesionales y al género (p. 70).

Ítem 3. El tópico gira en torno a "Social studies: a teenage survey" sobre las preferencias entre chicos y chicas de diferentes asignaturas y futuros trabajos:

The most popular jobs with girls:

Thirty per cent want to be doctors.

Twenty per cent want to be teachers.

Ten per cent want to be nurses.

The most popular jobs with boys:

Twenty-five per cent want to be sportsmen. 
Fifteen per cent want to be engineers.

Five per cent want to be mechanics.

Se nos transmite la idea de que las mujeres quieren ser doctoras, profesoras o enfermeras. Profesiones estas que perpetúan las tradicionales asignadas al género femenino. Por su parte, los chicos quieren ser deportistas de élite, ingenieros o mecánicos. Todas estas profesiones han sido las tradicionalmente asignadas al género masculino.

En relación a las asignaturas que prefieren los chicos y las chicas, los resultados de la encuesta no son muy reveladores y continúan apoyando la idea comentada anteriormente de los estereotipos del mundo laboral-género:

Chicos: Computer studies, Maths, English, Geography, Science, Languages, History.

Chicas: Languages, Science, English, Maths, Computer studies, History, Geography.

Mientras que la primera elección de los chicos es la Informática, las chicas prefieren los Idiomas. De aquí se pueden sacar una serie de conclusiones a nivel académico y cultural que nos llevan directamente a pensar que, por mucho que creamos que el mundo ha cambiado, debemos ser cautelosos y realistas y pensar que lo hace "muy lentamente" en relación a las cuestiones de género. Además, estas encuestas, verídicas o no, están realizadas a jóvenes que se supone deberían representar la parte más progresista de la sociedad y, sin embargo, no hacen más que seguir la línea cerrada que desde antiguo ha ido trazando la sociedad del patriarcado (p. 71).

Ítem 4. Aparece una foto con siete astronautas. Cinco de ellos son hombres y dos mujeres. Hay uno de origen asiático y otro negro.

El alcance de la fotografía es de gran calado porque presenta las diferencias de género y raza no como impedimento, sino como diferencias que no obstaculizan realizar una profesión de élite como puede ser trabajar para la NASA y viajar al espacio exterior (p. 37, workbook).

Ítem 5. Aparecen dos fotos de dos supermodelos de los años 90. Una de ellas corresponde a Claudia Schiffer y la otra a Naomi Campbell (negra). Esto tiene una serie de implicaciones en términos de raza. Es muy positivo que se presente a una mujer negra que sea capaz de llegar profesionalmente tan lejos como una top model de raza blanca.

El problema viene cuando ambas modelos, según propone la actividad, tienen que ser comparadas en términos de belleza. Aquí se destruye lo positivo de la actividad y se cae, incluso, en el más absoluto sexismo reduciendo la valía de estas mujeres a su belleza física (p. 41, workbook).

\section{Variable de orientación sexual}

Como es normal en los libros de texto, la editorial Oxford University Press no presenta de forma explícita ningún ejemplo visual o textual de los diferentes modelos que pueden presentar las parejas o las familias atendiendo a los parámetros de la orientación sexual. La línea de actuación, en este caso, es la omisión de estos temas presentando solamente a parejas heterosexuales y a familias constituidas por un padre, una madre y los hijos. 
JuAn RAMÓn GuiJarRo OJEDA La representación axiológica del género y la orientación sexual ...

\subsection{Editorial Cambridge University Press}

\section{Variable de género}

En relación a la variable de género, esta editorial intenta que las imágenes y los textos incluidos procuren en todo momento representar al género femenino y masculino en igualdad de oportunidades.

A continuación presentamos algunos ejemplos que respaldan esta situación:

Ítem 1. Bajo el título "Things we like doing”, se presenta un texto sobre una chica australiana, Julie Baker, de 16 años de edad cuyo principal hobby es pilotar helicópteros.

De esta forma se rompen los estereotipos de los hobbys y los deportes en torno a los géneros patriarcalmente establecidos. Aunque las imágenes y el texto presentados para la actividad son muy pertinentes; el tipo de actividades propuestas para con los mismos carecen de especial relevancia.

Generalmente, las actividades propuestas se limitan a extraer información del texto mediante preguntas de comprensión sobre el mismo (p. 22).

Ítem 2. "The secrets of success". Se presentan tres hombres y tres mujeres de éxito en la sociedad moderna y se analizan las razones de su éxito. Junto a estos personajes corren paralelos unos valores ocultos. Ellos son Bill Gates, David Beckam y Robbie Williams. Ellas son Penélope Cruz, J. K. Rowling y Naomi Campbell.

Este tipo de imágenes, textos y actividades resultan muy llamativos para los adolescentes y conllevan una carga de valores extraordinaria porque conectan muy bien con lo que los estudiantes reciben a diario a través de los medios de comunicación: esa cultura 'pop' de la Postmodernidad. Tanto en los personajes masculinos como femeninos seleccionados siempre hay un componente básico y esencial: todos son muy ricos. De esta forma, el dinero se establece como un valor absoluto e incuestionable que se transmite a los jóvenes.

En una actividad presentada para el texto se dan una serie de razones para tener éxito y que los estudiantes tienen que elegir. Entre estas razones encontramos: being lucky; being determined; having lots of money; being hard-working; having a dream; having rich parents; getting good school results; having good friends.

En otra de las tareas propuestas se pide lo siguiente: Think of someone you know who is successful but not famous. In what ways is this person successful? Discuss your ideas with a partner. Aquí pueden surgir cuestiones muy llamativas e interesantes en torno al papel que juega el género, la raza o la orientación sexual para determinar positiva o negativamente el éxito dentro de la sociedad occidental actual. Nuevamente, estas premisas, pensamos, deberían hacerse explícitas, bien por el propio libro de texto, bien por el profesorado encargado de impartir la asignatura.

No podemos olvidar que hay grandes cuestiones para discutir sobre la orientación sexual de personajes como Robbie Williams; cuestiones de género sobre J. K. Rowling, una de las mujeres-escritoras más populares del momento, acreedora de un premio Príncipe de Asturias; temas relacionados con la etnia de Naomi Campbell y su exacerbado éxito en el mundo de la moda donde los patrones están dominados por las mujeres de etnia blanca; o las cuestiones de identidad hispana y triunfo en Estados Unidos de la actriz española Penélope Cruz. (p. 62). 


\section{Variable de orientación sexual}

La diversidad de orientación sexual no se recoge de forma explícita presentando imágenes o textos que dé cuenta de ella. Al contrario, la situación imperante al respecto es la omisión de tales elementos constitutivos de la identidad.

Solamente hallamos un ejemplo en que un chico es discriminado por sus compañeros de clase porque se dedica a la danza en su tiempo libre. Aunque no se propone ningún tipo de actividades para despertar la discusión en torno a temas de identidad, el profesorado sí debería tomar en cuenta este texto para crear un debate sobre si porque a un chico le guste la danza tiene que ser necesariamente homosexual.

Los ejemplos de parejas o familias siempre cumplen patrones heterosexuales. Ni por la familia que se transmite, ni tampoco por el tipo de actividades que se presentan, se está aprovechando el alto potencial que tiene la introducción del tópico de la familia en el aula. Junto a la familia podrían explotarse temas de orientación sexual, de género, de roles sociales, de identidad, de sexualidad, de educación, etc. Por el contrario, tan sólo se introducen vocabulario, actividades de rellenar huecos y estructuras gramaticales (p. 14).

Ítem 1. Se trata el tema de la identidad en una sección titulada 'Different - so what?' Se expone de forma clara y realista la realidad discriminatoria de aquellos chicos que por ser hombres y gustarles hacer ballet, son duramente criticados por sus compañeros y amigos que ven en ese arte un afeminamiento inminente.

En uno de los diálogos podemos leer:

Dave: Oh, Tony. That's right. He goes to ballet classes.

Alex: Yeah, that' weird! A boy! Doing ballet!

Dave: Hey, Tony, do you want to play football with us?

Alex: Or are you worried about your pretty little dancing feet?

La introducción de estos diálogos es muy pertinente para tratar las cuestiones de género. El problema viene, una vez más, con el tipo de actividades diseñadas para explotar el texto. Hay que unir con flechas, completar frases y rellenar los huecos con fines estructurales o gramaticales (p. 26).

\section{Conclusiones generales}

Pensamos que el estudio de la muestra de los libros de texto que se utilizan en la actualidad en Inglés lengua extranjera puede resulta altamente beneficioso para el profesorado de esta área académica. El valor radica esencialmente en la importancia que tiene la transversalidad y la axiología en la educación integral del alumnado y, por tanto, requiere de la atención específica de los docentes en relación con los materiales que se utilizan.

De la descripción y análisis del corpus seleccionado de libros de texto, alcanzamos la conclusión de que la transversalidad está poco representada en los libros de inglés para la Educación Secundaria Obligatoria. Y no sólo la transversalidad, sino que la atención a la diversidad y las diferencias de 'Otredad' es bastante escasa. Hemos podido constatar, y al análisis nos remitimos, que todos los libros de texto analizados transmiten valores heterosexistas; en cambio, el sexismo se encuentra menos presente. 
JuAn RAMÓn GuiJarRo OJEDA La representación axiológica del género y la orientación sexual ...

Cuando se introducen elementos que son sustancialmente valiosos desde el punto de vista axiológico, el tratamiento metodológico y didáctico que se da a los mismos es superficial y se centra exclusivamente en elementos gramaticales o de desarrollo de destrezas lingüísticas. De esta forma, tender hacia la educación integral del alumnado desde el área de Lengua extranjera (inglés) es tarea harto complicada.

Queda mucho camino por recorrer en relación a los temas transversales y las cuestiones de Otredad en los materiales editoriales de Inglés Lengua Extranjera. Nuestra propuesta consiste en una labor consensuada de los departamentos de inglés en la creación de materiales axiológicamente significativos y constructivos para ser utilizados de forma discriminada en los momentos didácticos que sean requeridos en el proceso de enseñanza y aprendizaje.

\section{REFERENCIAS BIBLIOGRÁFICAS}

Burke, H. (2000). "Cultural diversity: managing same-sex orientation in the classroom." Ponencia presentada en TESOL-Spain el 26 de marzo 2000. Madrid.

Cunningsworth. A. (1984). Evaluating and Selecting EFL Teaching Materials. London: Heinemann. Cunningsworth, A. (1995). Choosing Your Coursebook. London: Heinemann.

Dooley, J. y Evans, V. (2004). Blockbuster 1. Newbury: Express Publishing. (Student's Book; Workbook \& Grammar Book).

Dubin, F. y Olshtain, E. (1986). Course Design. Cambridge: CUP.

Field, P. et al. (1998). Top Class 3. Limassol, Cyprus: Burlington Books. (Teacher's Manual; Teacher's Edition; Student's Book).

Heredia Maya, J. (2000). "Suecia sucia o la metáfora de cenicienta", en La mirada limpia o la existencia del otro, 1: 14-18.

Heredia Maya, J. (2001). "Justicia distributiva soy", en La mirada limpia o la existencia del otro, 10: 36-66.

Jiménez Catalán, R. (Coord.) (1997). Los temas transversales en la clase de inglés. Pamplona: Gobierno de Navarra.

Johnson, K. (1982). Communicative syllabus design and methodology. Oxford: Pergamon Press.

McDonough, J. y Shaw, C. (1993). Materials and Methods in ELT. Oxford: Blackwell.

Miranda, A. (1990). "The Vocabulary of the English Coursebooks: An Analysis" en RESLA, 6: 111119.

Mohamed, S. y Acklan, R. (1993). The Pre-Intermediate Choice. Longman. GreatBritain. (Student's Book; Workbook).

Molina, S. (1994). "Observaciones sobre el estado actual de la igualdad de oportunidades para ambos sexos en textos de inglés" en Encuentro. Revista deInvestigación e Innovación en la clase de idiomas, 7: 78-87.

Munby, J. (1978). Communicative Syllabus Design. Cambridge: Cambridge University Press.

Puchta, H. y Stranks, J. (2004). English in Mind. Cambridge: CUP.

Risager, K. (1990). "Cultural references in European textbooks: an evaluation of recenttendencies" en Buttjes, D. y M. Byram, Mediating Languages and Cultures. Multilingual Matters: Clevedon.

Rodríguez López-Vázquez, A. (2001). "El negro, indio y morisco en el teatro del Siglo de Oro", en La mirada limpia o la existencia del otro, 4: 18-31. 
Rueda, M. J. (1994). "Análisis de cuatro manuales para la enseñanza del español, lengua extranjera”, en REALE, 2: 79-114.

Selander, S. (1995). “Análisis del texto pedagógico”, en J. C. Minués y M. Beas Miranda (Comp.), Libro de texto y construcción de materiales curriculares. Granada: Proyecto Sur de Ediciones S.A. L.

Sheldon, L. (Ed.) (1988). "Evaluating ELT Textbooks and Materials", en ELT Journal, 42, 4: 23746.

Wildman, J., Whitney, N. y Falla, T. (1999). Thumbs up! 2. Oxford: OUP. (Guía didáctica para el profesor 2; Student's Book 2; Workbook 2). 